\title{
Dermatitis due to Acids
}

National Cancer Institute

\section{Source}

National Cancer Institute. Dermatitis due to Acids. NCI Thesaurus. Code C35309.

Contact dermatitis caused by exposure to acids. 